\title{
CDC25A, VAV1, TP73, BRCA1 and ZAP70 gene overexpression correlates with radiation response in colorectal cancer
}

\author{
MING-YII HUANG ${ }^{1,3}$, JAW-YUAN WANG ${ }^{2,4,5}$, HUI-JEN CHANG ${ }^{6,7}$, \\ CHIA-WEI KUO ${ }^{5}$, TECK-SIANG TOK ${ }^{8}$ and SHIU-RU LIN ${ }^{6,7}$
}

\begin{abstract}
${ }^{1}$ Department of Radiation Oncology, ${ }^{2}$ Division of Gastrointestinal and General Surgery, Department of Surgery, Cancer Center, Kaohsiung Medical University Hospital; Departments of ${ }^{3}$ Radiation Oncology, and ${ }^{4}$ Surgery, Faculty of Medicine, ${ }^{5}$ Graduate Institute of Medicine, College of Medicine, Kaohsiung Medical University, Kaohsiung 807; ${ }^{6}$ School of Medical and Health Science, Fooyin University, Kaohsiung Hsien 831; ${ }^{7}$ Department of Medical research, Fooyin University Hospital, Pingtung County 928; ${ }^{8}$ Department of Pediatrics, Pingtung Christian Hospital, Pingtung City 900, Taiwan, R.O.C.
\end{abstract}

Received October 28, 2010; Accepted December 13, 2010

DOI: $10.3892 /$ or.2011.1193

\begin{abstract}
Radiotherapy is increasingly used in adjuvant approaches for colorectal cancer (CRC) to reduce local recurrence and improve survival. However, the principal limitation is the large variability in response among different individuals due to tumor heterogeneity. In the present study, we compared gene expression profiles between radiosensitive and radioresistant colorectal cancer cell lines to identify radiation-related molecules that can be used to evaluate the effects of radiation. The CRC cell line SW620 was irradiated with a high-energy photo beam. Following radiation treatment, RNA was extracted from non-irradiated and irradiated cells, respectively, and gene expression analysis was performed by oligonucleotide microarray and the DAVID bioinformatics method. To further confirm the results, an additional 4 CRC cell lines, COLO205, T84, HCT116, SW480 and SW403 were purchased from ATCC. The radiosensitivities of each were determined by the survival fraction at 2 Gray (SF2) of the surviving cells using the ATPLite assay, and the gene expression profiles after irradiation among the radiosensitive and radioresistant cell lines were analyzed by membrane arrays. The relationships between gene expression and patient clinicopathological features were also analyzed using membrane arrays and RT-PCR. The results from oligonucleotide microarray analysis show that 1601 genes
\end{abstract}

Correspondence to: Dr Shiu-Ru Lin, School of Medical and Health Science, Fooyin University, 151 Chin-Hsueh Road, Ta-Liao Hsiang, Kaohsiung Hsien 831, Taiwan, R.O.C.

E-mail: srlin@ms2.hinet.net

Dr Teck-Siang Tok, Department of Pediatrics, Pingtung Christian Hospital, 60 Dalian Road, Pingtung City 900, Taiwan, R.O.C. E-mail: jjhua@seed.net.tw

Key words: CDC25A, VAV1, TP73, BRCA1, ZAP70, radiation response, colorectal cancer, microarray, membrane array were up-regulated (gene expression ratio of post- to preradiation treatment $>2$ ). By bioinformatic database analysis, 30 up-regulated genes were identified as involved in DNA damage response pathways, immune response pathways and the complement and coagulation cascades pathway. Fifteen genes showed differential gene expression profiles between radiosensitive (HCT116 and SW620) and radioresistant CRC cell lines (SW403 and SW480). In 110 CRC tissues, we detected five genes CDC25A, VAV1, TP73, BRCA1 and ZAP70 from 15 overexpressed genes that significantly related to prognostic factors (tumor size, advanced stage, invasive depth, lymph node metastasis and differentiation). These findings suggest that CDC25A, VAV1, TP73, BRCA1 and ZAP70 may be novel markers for predicting the effectiveness of radiotherapy in $\mathrm{CRC}$ patients.

\section{Introduction}

Colorectal cancer (CRC) remains one of leading causes of cancer mortality worldwide. Preoperative radiotherapy (RT) has been widely used as a major treatment modality to improve local control, as well as to improve survival (1-3). However, response to radiotherapy differs among individual tumors. In radiation unresponsive cases, there may have disadvantages such as delaying necessary surgery or immune suppression. Although many clinical factors $(4,5)$, radiological findings $(6,7)$, and molecular markers $(8,9)$ have been suggested to be related to the therapeutic response of CRC, the clinical usefulness of them to predict therapeutic response remains controversial. There are currently no reliable ways of identifying the individuals who may respond well to radiation. Thus, to identify factors that can be applied to predict RT efficacy before treatment will aid in making appropriate treatment strategy decisions.

Because cellular responses rely in part on changes in gene expression, the extent to which the radiation-responsive genes are induced or repressed influences how cells deal with radiation exposure, where individual variability of radiation sensitivity is observed at the gene expression level $(10,11)$. In 
2000, Lehnert et al reported that gene chips could be used to survey radiation-associated genes (12). Physicians explored different gene expression patterns between radiosensitive and radioresistant tumors in uterine cervical cancer (13), and to predict the clinical RT response in esophageal cancer (14) by microarray methods. However, the study of CRC and radiation-associated gene expression is still limited. Recently, there were two studies to identify the clinical preoperative RT response of rectal cancer, and was reported that tumor responsiveness was associated by gene profiling by microarrays (54 genes found by Ghadimi et al and 54 genes found by Watanabe et al) $(15,16)$. But such large numbers of gene profiles are difficult for physicians to effectively apply in clinical treatment decisions.

In 2004, Dairkee et al demonstrated that the gene expression of primary breast cancer cell cultures resembled tumor tissue (17). In the present study herein, we examined radiosensitivity in CRC cell lines to identify a set of discriminating genes that can be used for prediction of response to RT in human CRC. This laboratory utilized the high efficiency gene screening technology of microarrays to analyze the gene expression of irradiated CRC cells. From these tests we sought genes with radiation-related high expression that may serve as responsive markers. Therefore, we used paired irradiated and unirradiated SW620 cells (Dukes' C colorectal adenocarcinoma) and performed microarray analysis using the Agilent Oligo array. As a result, 1601 genes with expression levels in irradiated cells 1.5-fold higher than unirradiated cells were selected. We discovered 30 radiation-pathway related genes by employing bioinformatics studies. Using a membrane array, 15 out of 30 genes have more significant differences between radiosensitive and radioresistant cells. Results from this study demonstrated that five genes CDC25A, VAV1, TP73, BRCA1 and ZAP70 from 15 overexpressed genes were significantly related to clinicopathological factors (tumor size, advanced stage, invasive depth, lymph node metastasis and differentiation) which correlated to cancer prognosis in 110 stage I-IV CRC patients. These five genes might be potential new markers for radiation response prediction. Information of this nature is also of benefit in the selection of treatment options, as well as the assessment of individual response.

\section{Materials and methods}

ATCC cell lines and radiation. The cell lines used in this study were COLO205, HCT116, SW480, SW620 and SW403, five human CRC cell lines, which were obtained from ATCC (American Type Culture Collection, ATCC, Rockville, MD, USA). SW480, SW620 and SW403 cells were cultured in Leibovitz's L-15 medium, supplemented with $10 \%$ fetal bovine serum (FBS) and glutamine. COLO205 was cultured in RPMI-1640 medium supplemented with 5\% FBS and sodium pyruvate. HCT116 cells were cultured in McCoy's 5a medium supplemented with glutamine and 10\% FBS. All medium were added $1 \%$ antibiotic-antimycotic of cell cultivating solution and incubated at $37^{\circ} \mathrm{C}$ and $100 \%$ air. Cells were irradiated at room temperature, using a Medical LINAC (medical Linear accelerator). The energy of the photon beam was $6 \mathrm{MeV}$ with the dose rate of $400 \mathrm{mu} / \mathrm{min}$. The total dose of radiation was $2,4,6$ or 8 Gy to all CRC cell lines for radiation sensitivity analysis. The total dose of radiation was 16 Gy to SW620 cells for further microarray analysis of radiation-induced overexpression of genes.

ATPLite luminescence ATP detection assay for cell viability assessment. The radiosensitivities of cells were determined by survival fraction at 2 Gray (SF2) of the surviving cells (18). In the present study, the ATPLite assay (Packard Instrument Co., USA) was used to quantify viable cell density of the sample (19). Cells were harvested from exponential phase cultures by trypsinization, counted and then plated into 48 -well plates. Seeding densities were $10^{3}$ cells per well for each of the cell lines. Cells were incubated for 6 double times after radiation over the dose range 0-8 Gy. Subsequently $25 \mu \mathrm{l}$ of cell lysis buffer solution was added into each well and the substrate solution (luciferase/luciferin). ATPLite luminescence was measured in a TopCount Microplate reader (Packard Instrument Co.). The percentages of living cells were calculated per well. Results of SF2 from 6 replicate assays per cell line were analyzed.

Patients and tissue specimens. Enrolled in this study were 110 American Joint Commission on Cancer/International Union Against Cancer (AJCC/UICC) stage I-IV CRC patients (mean age, $62.07 \pm 10.85$ years) who underwent surgical treatment in the Department of Surgery at Kaohsiung Medical University Hospital, Taiwan. Patients with other malignant diseases in their medical history were excluded. All 110 patients underwent radical resection for a primary lesion. The data of these 110 CRC patients were used for analysis of radiation pathway-related gene expressions and the correlation between gene expression profiles and patient clinicopathological features. All paired samples including tumor and tumor-free tissues were obtained from all patients. Tumor grading was carried out and confirmed by pathologists. Each tissue sample was snap-frozen in liquid nitrogen immediately after surgery or biopsy, and stored at $-80^{\circ} \mathrm{C}$. Samples were further used in experiments for real-time PCR, membrane array analysis, and immunoblotting. Clinical stage and pathological features of primary tumors were defined according to criteria of the AJCC/UICC (20). Written informed consent was obtained from all subjects and/or guardians for the use of patient tissue samples. Tissue acquisition and subsequent use were approved by the institutional review board of Kaohsiung Medical University Hospital. Complete medical history, physical examination, and laboratory studies, including assessing serum carcinoembryonic antigen (CEA) levels were reviewed. Computed tomography (CT) or magnetic resonance imaging (MRI) of abdomen, abdominal ultrasonography, and chest radiography, bone scans, and colonoscopy were performed before surgical intervention.

Total RNA extraction and first strand cDNA synthesis. Total RNA was isolated from each CRC patient's tissue and from cell lines with ISOGEN ${ }^{\text {Tм }}$ (Nippon Gene, Toyama, Japan) and the QIAmp® Mini Kit (Qiagen Inc., Valencia, CA) according to the manufacturer's instructions (21). RNA purified is quantified by OD $260 \mathrm{~nm}$ by an ND-1000 spectrophotometer (Nanodrop Technology, USA) and quantitated by Bioanalyzer 2100 (Agilent Technology, Palo Alto, CA, USA). First strand 
cDNA was synthesized from total RNA by using a RT-PCR Kit (Promega Co., Madison, WI). The reverse transcription was carried out in a reaction mixture consisting of a $25 \mu \mathrm{g} / \mathrm{ml}$ oligo (dT) 15-mer primer, $100 \mathrm{mmol} / 1$ PCR Nucleotide Mix, $200 \mu \mathrm{mol} / 1 \mathrm{M}-\mathrm{MLV}$ Reverse Transcriptase, and $25 \mu \mathrm{l}$ of Recombinant RNasin ${ }^{\circledR}$ Ribonuclease Inhibitor (Promega). The reaction mixtures with RNA were incubated at $42^{\circ} \mathrm{C}$ for $2 \mathrm{~h}$ minimum, heated to $95^{\circ} \mathrm{C}$ for $5 \mathrm{~min}$, and then stored at $-80^{\circ} \mathrm{C}$ until analysis.

Oligonucleotide microarray analysis. The oligonucleotide array contains 22,500 elements designed for expression profiling (Human 1A V2, Agilent Technologies), for which over 18,000 well-characterized, full-length human genes have been defined. First-strand cDNA targets for hybridization were made by reverse transcription of the mRNA isolated from both the unirradiated and 12, 24, 48, $72 \mathrm{~h}$ after ionizing radiation (total dose $16 \mathrm{~Gy}$ ) from $\mathrm{SW620}$ cells by using SuperScript II RT (Gibco-BRL, Gaithersburg, MD, USA) in the presence of either Cy3- or Cy5-labeled dUTP (Amersham Pharmacia Biotech, Piscataway, NJ, USA). The targets were dried to $18 \mu \mathrm{l}$ by a SpeedVac ${ }^{\mathrm{TM}}$ concentrator (Thermo Electron Co., Waltham, MA, USA), and 3.6 $\mu 1$ 20X SSC, $1.8 \mu 110 \mathrm{mg} / \mathrm{ml}$ poly-A and $0.54 \mu 110 \%$ SDS were added. Then, the mixture was heated to $100^{\circ} \mathrm{C}$ for 2 min proceeding to the hybridization reaction on Human 1A Oligo Microarray V2 array slides (Agilent Technologies) in an incubator at $60^{\circ} \mathrm{C}$ for $17 \mathrm{~h}$. After being sequentially washed with $1 \mathrm{X} \mathrm{SSC}$, $0.2 \mathrm{X}$ SSC and $0.5 \mathrm{X}$ SSC, hybridized microarray slides were scanned and fluorescence signals were detected by using an Axon GenePix Pro 3.0 ${ }^{\mathrm{TM}}$ (Axon Instruments). The acceptance criterion for a gene signal was a signal-to-noise ratio of $\geq 2$. If either the Cy3 or Cy5 signal of a specific spot passed the criterion, the flag of its ratio was counted to be 'True'. The element with the 'True' flag was analyzed with GeneSpring GX7 (Silicon Genetics, Redwood City, CA, USA). The differentially expressed elements were analyzed by the two-sided statistical tolerance interval (95\%).

Real-time polymerase chain reaction (RT-PCR). For each reaction, $2.0 \mu \mathrm{l}$ of each cDNA sample were used. Sequences of the 30 oligonucleotide primers were designed according a PCR primer selection program based on primer 3 at http:// frodo.wi.mit.edu/cgi-bin/primer3/prime3www.cgi (Table I). Each RT-PCR reaction mixture contained $1 \mathrm{X}$ PCR buffer (10 mmol/1 Tris- $\mathrm{HCl}, \mathrm{pH} 8.3,50 \mathrm{mmol} / 1 \mathrm{KCl}, 2 \mathrm{mmol} / 1$ $\left.\mathrm{MgCl}_{2}\right), 50 \mu \mathrm{mol} / 1 \mathrm{dNTP}, 0.1 \mu \mathrm{mol} / 1$ sense and antisense primers for target genes, and $0.1 \mu \mathrm{mol} / 1$ sense and antisense primers for $\beta$-actin. PCR products were analyzed on $3 \%$ agarose gel containing $0.5 \mu \mathrm{g} / \mathrm{ml}$ ethidium bromide. The signals on the UV transilluminator for each target gene and $\beta$-actin expression levels were scanned with a computing laser densitometer (Alpha Inotech, San Leandro, CA) to calculate the reactive mRNA density. Real-time PCR was performed in a Rotor-Gene 2000 thermocycler (Corbett Research, Inc.). PCR products (i.e. synthesized dsDNA) were quantified by measuring the fluorescent intensity at the end of each amplification cycle. For each sample, real-time PCR analysis was repeated in three independent experiments to ensure the reproducibility of results. We used $\beta$-actin and Oryza sativa sequence individual to be positive and negative controls, respectively, and used dd water to be a blank control.

Membrane array. The procedure of the membrane-array method for gene detection was performed based on our previous work (22). Visual OMP3 (Oligonucleotide Modeling Platform, DNA Software, Ann Arbor, MI) was used to design probes for target genes and $\beta$-actin, and the latter served as an internal control (Table I). The newly synthesized oligonucleotide fragments were dissolved in distilled water to a concentration of $20 \mathrm{mM}$, applied to a BioJet Plus $3000 \mathrm{nl}$ dispensing system (BioDot Inc., Irvine, CA, USA), which blotted the target oligonucleotide, and the $\beta$-actin control sequentially $(0.05 \mu \mathrm{l}$ per spot and $1.5 \mathrm{~mm}$ between spots) on SuPerCharge nylon membrane (Schleicher and Schuell, Dassel, Germany) in triplicate. DMSO was also dispensed onto the membrane as a blank control (Fig. 1). After rapid drying and cross-linking procedures, the preparation of membrane array was accomplished. The membrane array was used to analyze the gene expression among the radiosensitive and radioresistant CRC cell lines (Fig. 2); and to compare gene expression of tumor and normal counterpart tissue in 110 CRC patients.

Preparation of digoxigenin (DIG)-labeled cDNA targets and hybridization. First-strand cDNA targets for hybridization were made by reverse transcription of the mRNA from the tumor and corresponding normal tissues of CRC patients in the presence of DIG-labeled UTP (Roche Diagnostics GmbH, Penzberg, Germany) using SuperScript II reverse transcriptase (Gibco-BRL). The hybridized arrays were then scanned with an Epson Perfection 1670 flatbed scanner (SEIKO Epson Corp., Nagano-ken, Japan). Subsequent quantification analysis of each spot's intensity was carried out using AlphaEase ${ }^{\circledR}$ FC software (Alpha Innotech Corp.). Spots consistently carrying a factor of two or more were considered as differentially expressed. A deformable template extracted the gene spots and quantified their expression levels by determining the integrated intensity of each spot after background subtraction. The fold ratio for each gene was calculated as follows: spot intensity ratio $=$ mean intensity of target gene/mean intensity of $\beta$-actin. Fig. 1 provides the schematic representation of the membrane array with 30 target genes, one housekeeping gene $(\beta$-actin), one bacterial gene (TB), and the blank control (dd water).

Statistical analysis. All data were analyzed by using the statistical Package for the Social Sciences Version 12.0 software (SPSS Inc.). The correlation between SF2 of five CRC cell lines was analyzed by one-way ANOVA. Gene expression profiles between radiosensitivity and radioresistant cell lines were analyzed by the Independent t-test. The correlation between the clinicopathological features and gene expressions in CRC patients was compared using the $\chi^{2}$ test. $\mathrm{P}<0.05$ was considered statistically significant.

\section{Results}

Microarray analysis of colorectal cell lines. SW620 cells were irradiated with 16 Gy to induce sublethal DNA damage 
Table I. Oligosequences of 30 target genes which related to the radiation associated genetic pathway by BIOCATA and KEGG database analysis after microarray analysis.

Gene name

Oligonucleotide sequence

Complement and coagulation

cascades

CFI

PTGS1

CFB

PROCR

FGA

VWF

F2

FGG

PLG

DbpB (YBX1)

TGCACAGCCAACTTCATCTTCCCCTGTAATGCAGTCCACCTCACCATT ATAGCCCAACCAAACTGACAAATAAAACCAACCATCACATCCACCAAATC TCCTTCAGCCAGGGCAGCACTTGAAAGAGGTTGATGTGAAAGTCTCG CCCTATTATATCAGCGTCCCATCCCAAGTCTGACACACCTGGAAGTATTG ATGTGCCTAAATCCATTGCCTCGGGACAGTCAGAACCATCTTCGGAG CCTGCACATCGTTGATGTCAATGGAGTACATGGCTTTGCTGGCACATT CCAAAGGTCCTCGGATTGAAGAAAGTCTGGTACTCACTGGTGGCGGTACG TGGTGTTGCTGTCCTTCTCCAATTGTGAGTCTGTTGAATGGGATTATCTT CACAATCAAATGAAGGGGCCGCACACTGAGGGACATCACAGTAGTCGTAA

Immunization

ANPEP

CXCR4

PTPN7

TLR2

CD33

$\mathrm{RHOH}$

ZAp70

IL8

VAV1

CD59

ICAM1

GGACCTGTAACATTTGCTGCCTCCGCACCCTTTTCTCCTTCAACAACATC

DNA damage response

CASP1

TP73

TGFB2

SMC1B

BRCA1

CDC25A

RAD51

ESPL1

CDKN1A (p21)

\begin{abstract}
CATACTCGGTGGAGAATCGTCGTGTCACTGCCTGGATGAGGTTGGA
GAAACTGGAACACAACCACCCACAAGTCATTGGGGTAGAAGCGGTCA

TCAGGGAGCAGAGTCACTGATAGGATGTTGAGACTTGGAGATCAGGACCA

TCAATGATATTGTCAATGATCCACTTGCCAGGAATGAAGTCCCGCTTAT

AATCTCCAAGAATCAGCCTTTGGTCCCCGACCTGTAGAGGATGTGGATCT

AGGGCAAGTTGCTCCTAATTTCACCAATCCACTTGTTCTTCAAGTTCAGG

TCAAGAGGGAAGCTGGGTTTATTCTGGTGATCTACGCCTGACCACCTGA

AATTCTCAGCCCTCTTCAAAAACTTCTCCACAACCCTCTGCACCCAG

TAGTAGATGTATTTCTGCCCTCCCACCAGTTCTGTTCAGCCTCAGCCTTC GCATGTAAGGTTAAGTAACTTGCCTGAGGGTCGCCGATTAGCATCAGAGC CCCATTATGACTGCGGCTGCTACCACAGTGATGATGACAATCTCATACCG
\end{abstract}

CTACCATCTGGCTGCTCAAATGAAAATCGAACCTTGCGGAAAATTTCCTC TGGTAAATGCTCTGTAACCCTTGGGAGGTGAAATACTCGATGCAGTTTGG CTTTCACCAAATTGGAAGCATTCTTCTCCATTGCTGAGACGTCAAATCGA CCACACACTTTTCTCCCCCTGACAAATTGTCCATTGGCATAAACCGTT TCATTTCTAATACCTGCCTCAGAATTTCCTCCCCAATGTTCCACTCCAAC ACCAAGCTCCCTCCTGAGAAAATTCTATCCAGTCATGTCCATGCCAGCAC CTGAAAGCTCACCTCGACCCGAGTAGTCTGTTCTGTAAAGGGCGGTGG TCACATCCCAGAGATTACCCAGAAACAAGGGGCAACCAGCCATGATGTAC

CFI, complement factor I; PTGS1, prostaglandin-endoperoxide synthase 1; CFB, complement factor B; PROCR, protein C receptor, endothelial; FGA, fibrinogen $\alpha$ chain, transcript variant $\alpha$; VWF, von Willebrand factor; F2, coagulation factor II (thrombin); FGG, fibrinogen $\gamma$ chain, transcript variant $\gamma$-A; PLG, plasminogen, mRNA; dbpB, DNA-binding protein B; ANPEP, alanyl (membrane) aminopeptidase; CXCR4, chemokine (C-X-C motif) receptor 4; PTPN7, protein tyrosine phsophatase, non-receptor type 7; TLR2, toll-like receptor 2; CD33, CD33 molecule; RHOH, ras homolog gene family, member $\mathrm{H}$; ZAp70, -chain (TCR) associated protein kinase $70 \mathrm{kDa}$; IL8, interleukin 8; VAV1, vav 1 guanine nucleotide exchange factor; CD59, CD59 molecule, complemetnt regulatory protein, transcript variant 1; ICAM1, intercellular adhesion molecule 1, human rhinovirus receptor; CASP1, caspase-1, apoptosis-related cysteine peptidase; TP73, tumor protein p73; TGFB2, transforming growth factor $\beta-2$ precursor; SMC1B, structural maintenance of chromosomes 1B; BRCA1, breast cancer 1; CDC25A, cell division cycle 25 homolog A; RAD51, RAD51 homolog; ESPL1, extra spindle pole bodies homolog 1; CDKN1A (p21), cyclin-dependent kinase inhibitor $1 \mathrm{~A}$.

and were incubated at four time points $(12,24,48$ and $72 \mathrm{~h}$, respectively). We utilized four groups of cells with different incubation durations and paired them with cells without radiation. All results from the experiments underwent standardized analysis and validation. Then, we used GeneSpring Biological data analysis software, where hierarchical clustering was performed in the experimental groups to initially assess gene expression of all genes on the chip. After further analysis and validation, 1601 genes displayed overexpression and potentially served as biological markers. 


\begin{tabular}{|c|c|c|c|c|c|c|c|c|c|c|c|}
\hline VIWF & F2 & FGG & FGA & PLG & dbpB & PROCR & PTGS1 & CF1 & CFB & Blank & $\beta$-actin \\
\hline VIFF & F2 & FGG & FGA & PLG & dbpB & PROCR & PTGS1 & CF1 & CFB & Blank & $\beta$-actin \\
\hline VIFF & F2 & FGG & FGA & PLG & dbpB & PROCR & PTGS1 & CF1 & CFB & Blank & $\beta$-actin \\
\hline ANPEP & CD33 & TLR2 & ZAP70 & IL8 & CXCR4 & VAV1 & RHOH & ICAM1 & PTPN7 & CD59 & Blank \\
\hline ANPEP & CD33 & TLR2 & ZAP70 & IL8 & CXCR4 & VAV1 & RHOH & ICAM1 & PTPN7 & CD59 & Blank \\
\hline ANPEP & CD33 & TLR2 & ZAP70 & IL8 & CXCR4 & VAV1 & RHOH & ICAM1 & PTPN7 & CD59 & Blank \\
\hline TGFB2 & P21 & CDC25A & SMC1B & ESPL1 & RAD51 & BRCA1 & CASP1 & TP73 & Blank & Blank & $\beta$-actin \\
\hline TGFB2 & P21 & CDC25A & SMC1B & ESPL1 & RAD51 & BRCA1 & CASP1 & TP73 & Blank & Blank & $\beta$-actin \\
\hline TGFB2 & P21 & CDC25A & SMC1B & ESPL1 & RAD51 & BRCA1 & CASP1 & TP73 & Blank & Blank & $\beta$-actin \\
\hline
\end{tabular}

Figure 1. Location of dotting on gene array nylon membranes. The arrangement of gene dotting on the nylon membranes is demonstrated. Each tested gene was dotted three repeated times on the nylon membrane. On the right side, three repeated dots of negative control (TB, tuberculosis gene); three repeated dots of positive control ( $\beta$-actin) and three repeated dots of blanks (50\% DMSO).
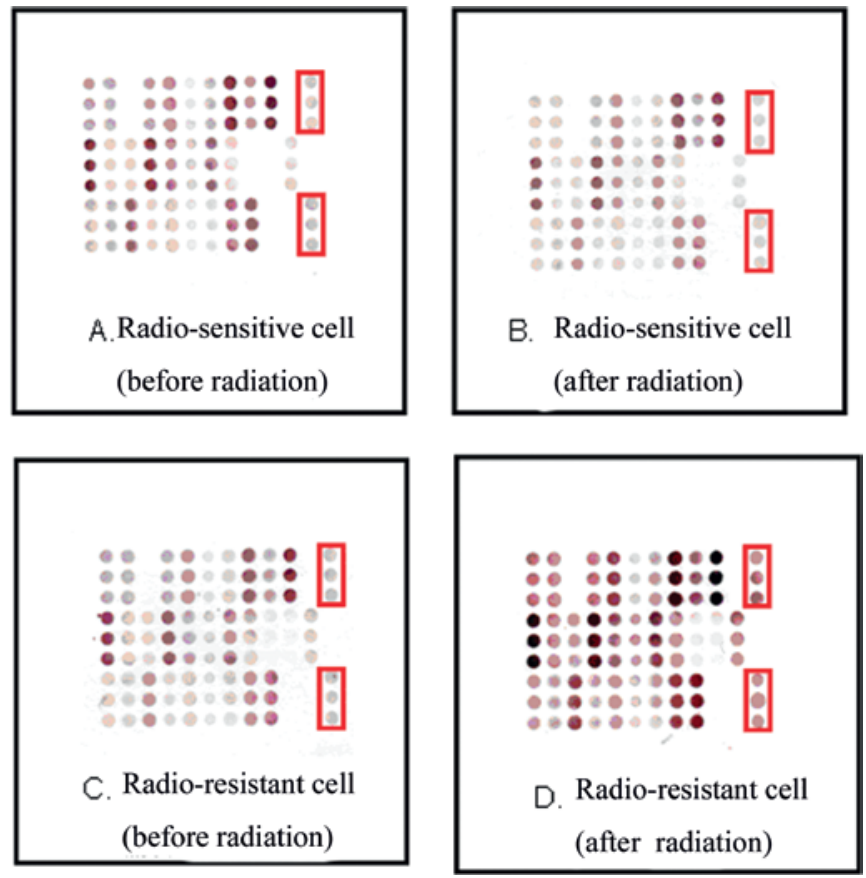

Figure 2. Results of color expression of Nylon membrane gene array. Color effects of the 30 target genes on nylon membranes are shown. (A and B) The genetic expression of unirradiated and irradiated HCT116 cell lines. (C and D) The genetic expression of unirradiated and irradiated SW403 cell lines.

Identification of candidate genes by bioinformatics and ATCC cell lines. The 1601 overexpressed gene validated in the SW620 cells, were analyzed with DAVID (Database for Annotation, Visualization, and Integrated Discovery) (23), and KEGG (Kyoto Encyclopedia of Genes and Genomes) databases (24), and results indicated that a total of 30 genes, and 3 identified pathways were enriched for genes associated with radiation response, including the DNA damage response, immunization and complement and the coagulation cascade. The constructed radiation-associated genetic pathway is shown in Fig. 3.

Radiosensitivity of colorectal cancer cell lines. The doubling time of five CRC cell lines, SW480, SW403, COLO 205, SW620 and HCT116, were examined and data are shown in Table II. SW403 has the longest doubling time, and HCT116 displayed the shortest doubling time. The SF2 of each cell line is shown in Table II and exhibited statistical significance $(\mathrm{P}=0.0034)$. The SF2 values of SW403, SW480 and COLO 205 cell lines were significantly larger than SW620 and HCT116 cell lines. Therefore, SW620 and HCT116 cell lines were categorized to be radiosensitive cell lines, and SW403, SW480 and COLO 205 cell lines were identified as radioresistant cell lines.

Differential gene expression between radiosensitive and radioresistant cell lines. To investigate the expression profiles of the afore-mentioned 30 genes in the four CRC cell lines with different radiation sensitivity, membrane array was used to detect the 30 gene expression levels from SW620, HCT116, SW403 and SW480 cells. The differential gene expression profiles of four CRC cell lines are shown in Table III. Using statistical independent t-test analysis, we found that there were 


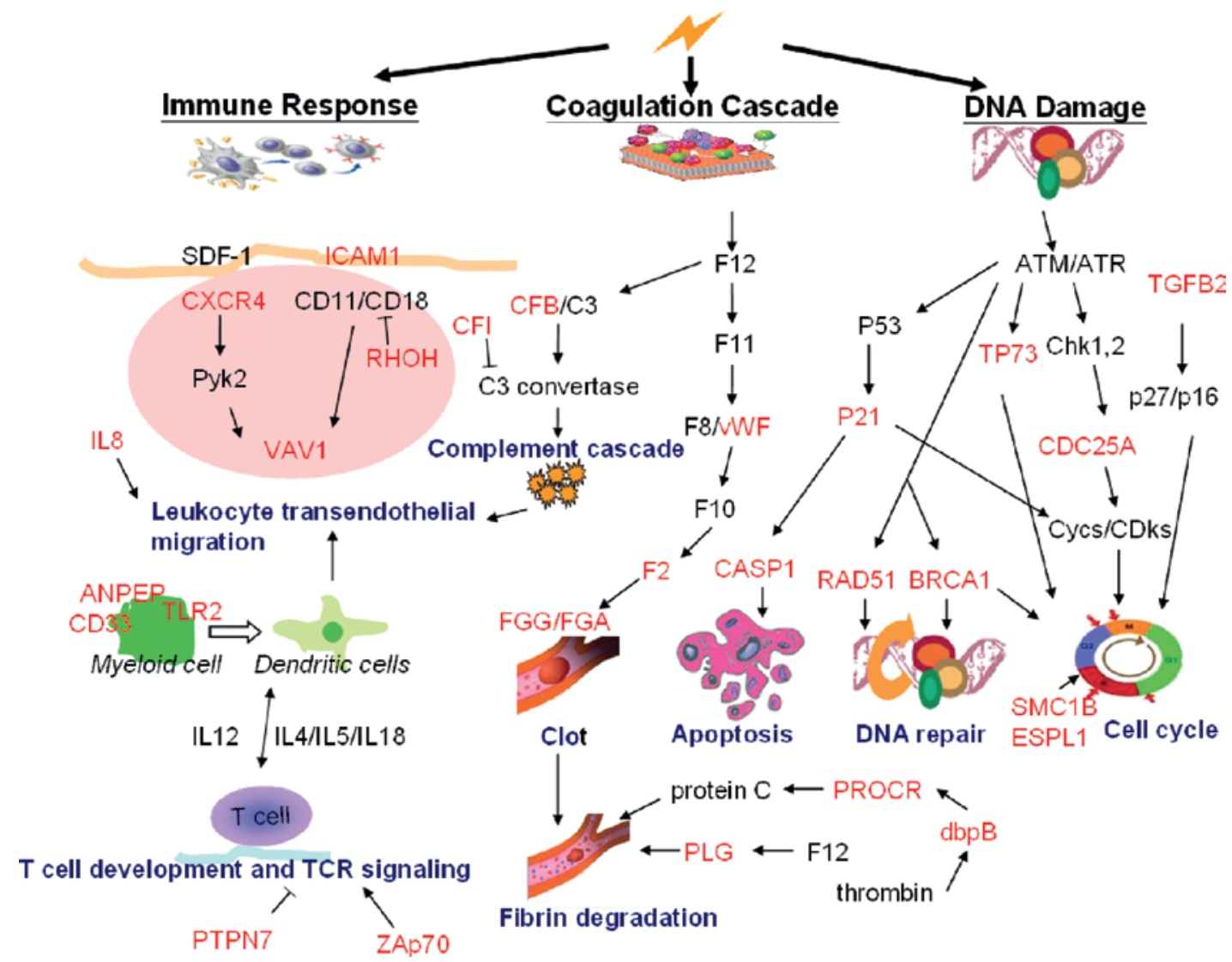

Figure 3. Radiation related pathways. There were three radiation related pathways including immune response, coagulation cascade and DNA damage pathways.

Table II. The doubling times and survival fraction at 2 Gray (SF2) of six colorectal cell lines.

\begin{tabular}{|c|c|c|c|c|c|c|}
\hline Cell lines & Disease & $\begin{array}{c}\text { Stage } \\
\text { (Dukes') }\end{array}$ & $\begin{array}{l}\text { Doubling time }(\mathrm{h}) \\
\quad(\text { mean } \pm \mathrm{SD})\end{array}$ & $\begin{array}{l}6 \text { doubling time } \\
\text { (day) }\end{array}$ & $\begin{array}{l}\text { Measure time } \\
\quad \text { (day) }\end{array}$ & $\underset{\%}{\mathrm{SF} 2(\operatorname{mean}} \pm \mathrm{SD})$ \\
\hline SW480 & Colorectal adenocarcinoma & B & $30.65 \pm 1.29$ & 7.6 & 8 & $59.17 \pm 0.59$ \\
\hline SW403 & Colorectal adenocarcinoma & $\mathrm{C}$ & $71.47 \pm 9.12$ & 17.86 & 18 & $58.97 \pm 1.37$ \\
\hline COLO205 & Colorectal adenocarcinoma & $\mathrm{D}$ & $31.45 \pm 2.69$ & 7.86 & 8 & $54.16 \pm 10.56$ \\
\hline SW620 & Colorectal adenocarcinoma & $\mathrm{C}$ & $28.92 \pm 5.62$ & 7.23 & 8 & $32.55 \pm 5.14$ \\
\hline HCT116 & Colorectal adenocarcinoma & $\mathrm{ND}^{\mathrm{a}}$ & $16.23 \pm 0.84$ & 4.05 & 5 & $24.88 \pm 0.12$ \\
\hline
\end{tabular}

${ }^{\mathrm{a} N D}$, no data.

15 out of 30 genes with significant differential expression between radiosensitive and radioresistant CRC cells.

Gene validation in clinical colorectal cancer tissues by membrane array and RT-PCR. The afore-mentioned 15 genes which had significant differential expression between radiosensitive and radioresistant $\mathrm{CRC}$ cells, were validated in the colorectal tissues of clinical stage I-IV CRC patients, both membrane array and RT-PCR were conducted to detect the mRNA expression level from the 110 paired tissues. Based on the results of membrane array hybridization analysis, if the gene presented a color response of $>2$-fold between the CRC cancer and normal tissue, it was defined as overexpression.
As shown in Table IV, we compared the correlation between gene expression and clinicopathological features of 110 CRC patients. Statistical analysis indicated that five genes, CDC25A, VAV1, TP73, BRCA1 and ZAP70, have a statistically significantly correlation to prognostic factors (including tumor size, advanced stage, invasive depth, lymph node metastasis and differentiation) $(\mathrm{P}<0.05)$.

\section{Discussion}

Preoperative radiotherapy has been widely used to improve local control of disease and to improve survival in the treatment of rectal cancer. However, there is a wide spectrum 
Table III. Differential gene expression between radiosensitive and radioresistant cell lines.

\begin{tabular}{|c|c|c|c|}
\hline Pathway/genes & $\begin{array}{c}\text { HCT116 } \\
\text { vs. SW480 }\end{array}$ & $\begin{array}{c}\text { HCT116 } \\
\text { vs. SW403 }\end{array}$ & $\begin{array}{c}\text { SW620 } \\
\text { vs. SW403 }\end{array}$ \\
\hline \multicolumn{4}{|l|}{$\begin{array}{l}\text { Complement and } \\
\text { coagulation } \\
\text { cascades }\end{array}$} \\
\hline CFI & - & - & - \\
\hline PTGS1 & a & a & - \\
\hline CFB & a & a & - \\
\hline PROCR & - & - & - \\
\hline FGA & - & - & - \\
\hline VWF & - & - & - \\
\hline $\mathrm{F} 2$ & - & - & - \\
\hline FGG & - & - & - \\
\hline PLG & - & - & - \\
\hline DbpB & - & - & - \\
\hline \multicolumn{4}{|l|}{ Immunization } \\
\hline ANPEP & a & - & - \\
\hline CXCR4 & a & a & - \\
\hline PTPN7 & - & - & - \\
\hline TLR2 & - & - & - \\
\hline CD33 & - & - & - \\
\hline $\mathrm{RHOH}$ & - & - & - \\
\hline ZAp70 & a & a & $\mathrm{a}$ \\
\hline IL8 & a & a & - \\
\hline VAV1 & a & a & $\mathrm{a}$ \\
\hline CD59 & a & $\mathrm{a}$ & - \\
\hline ICAM1 & $\mathrm{a}$ & a & - \\
\hline \multicolumn{4}{|l|}{$\begin{array}{l}\text { DNA damage } \\
\text { response }\end{array}$} \\
\hline CASP1 & a & a & - \\
\hline TP73 & a & a & $\mathrm{a}$ \\
\hline TGFB2 & a & - & - \\
\hline SMC1B & - & - & - \\
\hline BRCA1 & $\mathrm{a}$ & $\mathrm{a}$ & $\mathrm{a}$ \\
\hline $\mathrm{CDC} 25 \mathrm{~A}$ & $\mathrm{a}$ & $\mathrm{a}$ & $\mathrm{a}$ \\
\hline RAD51 & - & a & - \\
\hline ESPL1 & - & - & - \\
\hline p21 & - & - & - \\
\hline
\end{tabular}

${ }^{\mathrm{a}}$ Gene carried differential gene expression profiles between two cell lines with statistical significance.

of tumor responsiveness of rectal cancer to preoperative radiotherapy ranging from complete response to complete resistance. Pretreatment tumor intrinsic radiosensitivity is an important prognostic parameter, and contributes to prognosis independently of other established and putative parameters (25). In past studies, several genes were found to associate with radiation sensitivity, such as p53 (26-30), ras (31), raf-1 (32), and bcl2 $(29,30)$, and they were related to DNA repair, apoptosis, cell cycle, growth factors, signal transduction and cell adhesion. In spite of some studies reporting radiation sensitivity associated with a gene in CRC, they were largely focused on single genes $(26,33)$. A few studies have conducted comprehensive gene expression profiles by microarray analysis, but the mechanism of radiation sensitivity was still unclear $(15,16,34)$.

SF2 was reported to be independent of prognostic factors of disease stage, tumor grade, patient age, colony-forming efficiency and tumor diameter in cancers (25). In the present study herein, we applied SF2 to classify CRC cell lines to be either radiosensitive or radioresistant groups. We began with gene expression response to radiation because cellular responses rely on changes on gene expression. Irradiation of cells may not only lead to cell death but to other changes as well. Many factors affect radiation response including the position of tumor cells within the cell cycle, which may confer radiosensitivity or resistance. For instance, the late G2 and M phases are the most radiosensitive, whereas the late $S$ phase is the most radioresistant $(35,36)$. Bioinformatics resources provide a comprehensive set of functional annotation tools for investigators to understand biological meaning behind large lists of genes. Microarray results of irradiated CRC cells were analyzed by DAVID (23), and KEGG (24) databases and the data identified 30 unregulated genes within DNA damage response, immunization and complement and coagulation cascade pathways. By determining 30 radiation-associated gene expression profiles using membrane array, we identified 15 novel discriminating genes of which the expression differed significantly between radiosensitive and radioresistant cell lines. The list of discriminating genes included PTGS1, CFB, ANPEP, CXCR4, ZAp70, IL8, VAV1, ICAM1, CD59, CASP1, TP73, BRCA1, CDC25A, RAD51 and TGFB2. In 2007, Knoops et al firstly reported irradiation-induced genes related to macrophage activation and immune response in follicular lymphoma patients (37). According to analysis of the complement and coagulation cascades pathway, previous studies have linked malignant transformation, tumor angiogenesis and metastasis to the generation of clotting intermediates (e.g. tissue factor, factor Xa and thrombin), clotting or platelet function inhibitors (e.g. COX-2), or fibrinolysis inhibitors (e.g. plasminogen activator inhibitor, type 1) (38-40); and an in vitro study used low frequency electrical fields to induce up-regulated genes related to hemostasis by microarray (41).

After validation in 110 clinical stage I to IV CRC patient tissues, CDC25A, VAV1, TP73, BRCA1 and ZAP70 were selected from 15 radiation-related genes to be the prognosisrelated markers depending on their significant correlations to clinical prognostic variables. CDC25A, TP73 and BRCA1 are associated with the pathway of DNA damage response; ZAP70 and VAV1 are associated with the immune-related pathway. The five genes have also been reported to be prognostic factors in other cancers.

CDC25A was overexpressed in various human malignancies including non-Hodgkin's lymphoma, non-small cell lung cancer, and esophageal cancer (42-44), and also overexpressed in axoxymethane-induced murine colon cancer (45). CDC25A, CDC25B and CDC25C belong to a family of protein phosphatases which activate the cyclin-dependent kinases at different points of the cell cycle (46). Disorders of the cell cycle and cell cycle-regulating molecules are characteristics of cancer cells. Some of these disorders greatly affect the clinical outcome, independently of other 


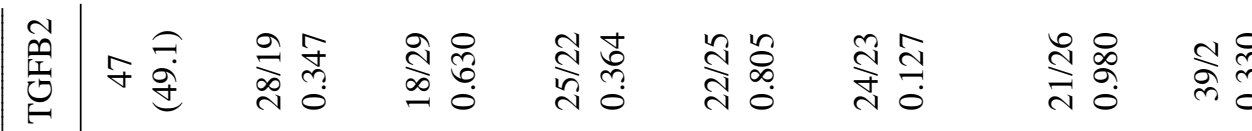

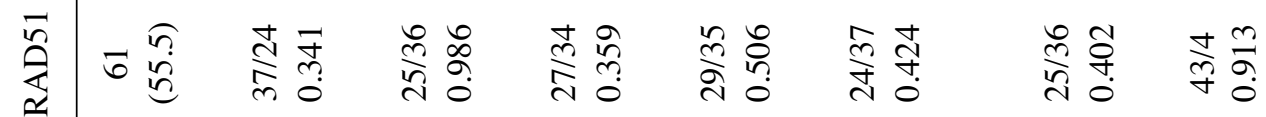

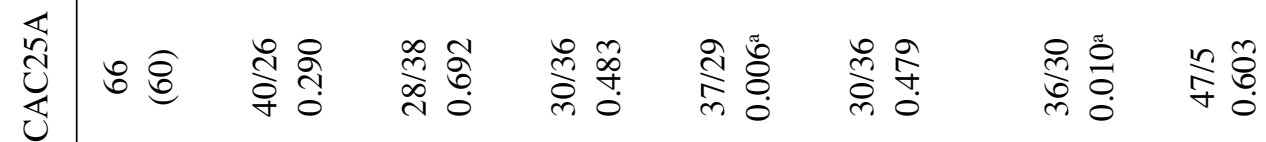

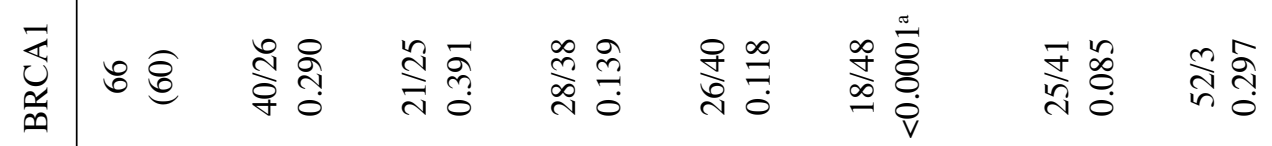

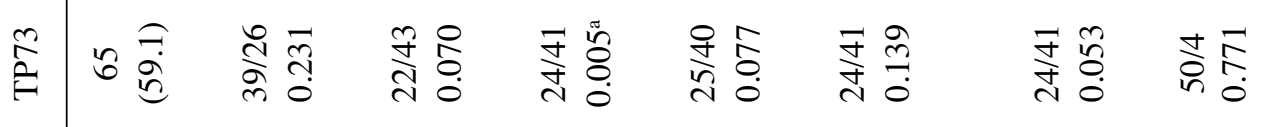

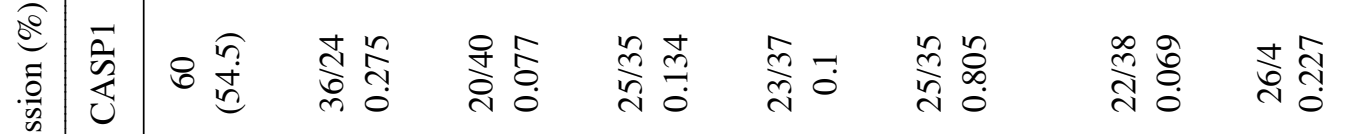

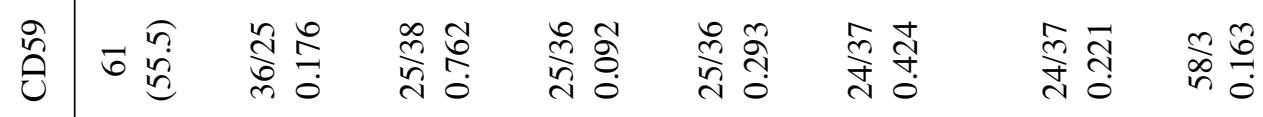

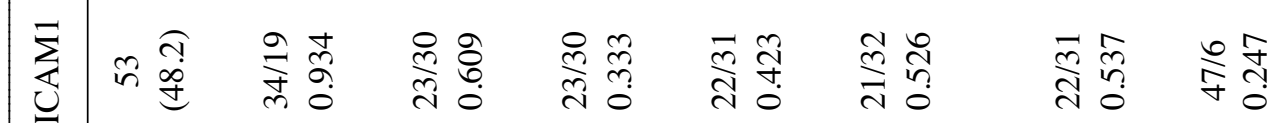

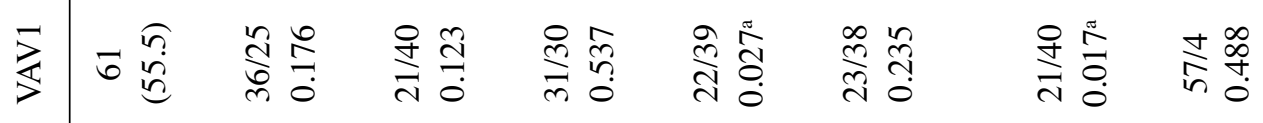

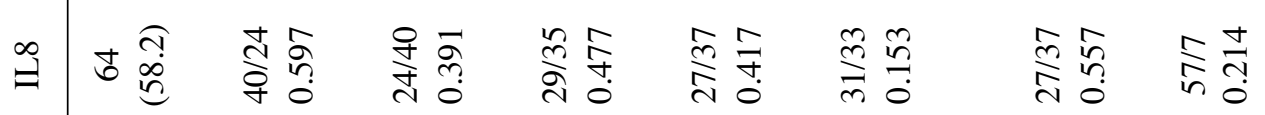

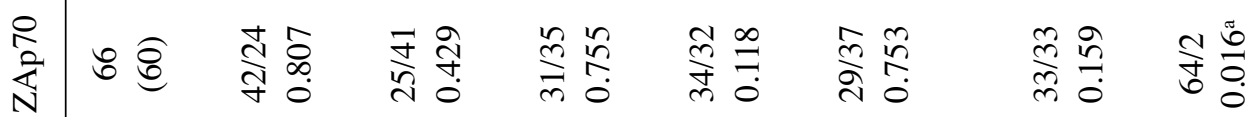

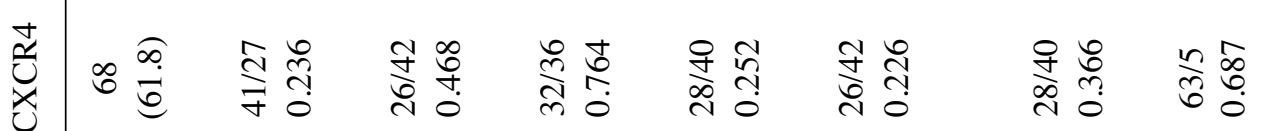

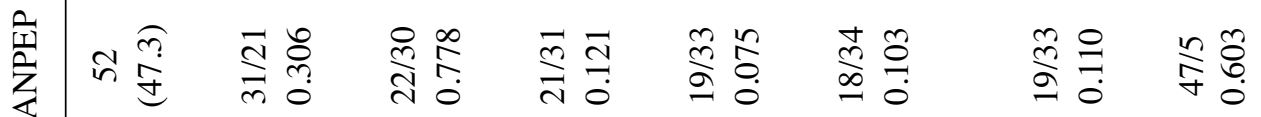

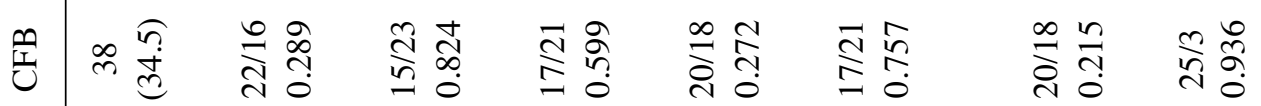

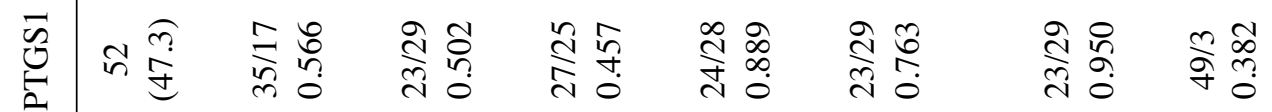

(1)

$\dot{i} \quad \stackrel{\curvearrowright}{\Sigma}$

$\frac{\sqrt{2}}{\sqrt[3]{2}}$

$\underset{\substack{n \\ n}}{n}$

है

$\frac{\widehat{\sigma}}{\stackrel{+}{+}}$

$\stackrel{\widehat{0}}{\frac{0}{9}}$

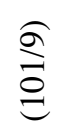

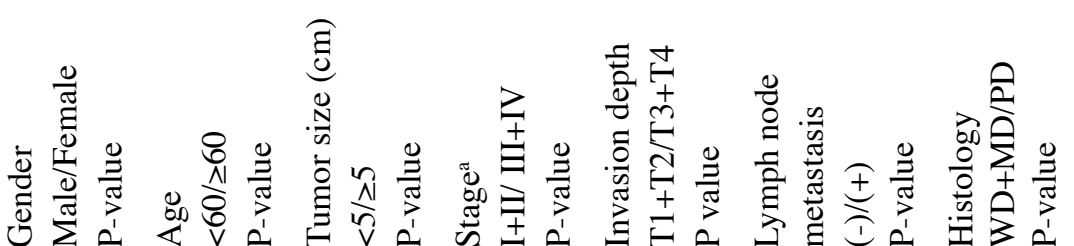


clinicopathological parameters, and have been found to be associated with sensitivity for radiotherapy via induction of tumor cell apoptosis (47). In 2000, Miyata et al found that CDC25B overexpression was associated with a high sensitivity for radiation therapy in human esophageal cancer (48). Postoperative survival was found poorer for CDC25Apositive esophageal squamous cell carcinoma patients (44). In the present study, CDC25A overexpression is more strongly associated with CRC patients with earlier cancer stage or without lymph node metastasis. In hepatocellular carcinomas, high TP73 expression levels were revealed as an independent prognostic marker of poor survival (49). TP73 overexpression is more associated with CRC patients with tumor size larger than $5 \mathrm{~cm}$ in our study. BRCA1 had been reported to be involved in the radiotherapy resistance of breast cancer (50). In this study, BRCA1 overexpression is associated with CRC patients with deeper tumor invasion earlier cancer stage (T3+T4) with statistical significance.

ZAP-70 expression has been associated with disease progression in patients with chronic lymphocytic lymphoma (51). In the present study, ZAP-70 overexpression is associated with CRC patients with well and moderate differentiated histology. VAV1 was reported to act as a growth-stimulatory protein in primary pancreatic adenocarcinoma (52). VAV1 overexpression is noted associated with CRC patients with advanced cancer stage or with lymph node metastasis in this study.

Our results have medical implications. The genes particularly identified in this study will enable the genetic prediction of individualized sensitivity to RT. In addition, the identification of genes involved in regulating radiation response will enable the development of radiosensitizers that increase the sensitivity of tumor(s) to radiation. We suggest that pretherapeutic gene expression profiling may assist in response prediction of CRC to RT. The implementation of gene expression profiles for treatment stratification and clinical management of cancer patients requires validation in large independent studies.

\section{Acknowledgements}

This work was supported by grants from the Kaohsiung Medical University Hospital (KMUH95-5D18), the Kaohsiung Medical University (KMU-M096012), and Excellence for Cancer Research Center Grant through funding by the Department of Health, Executive Yuan, Taiwan, Republic of China (DOH100-TD-C-111-002).

\section{References}

1. Improved survival with preoperative radiotherapy in resectable rectal cancer. Swedish rectal cancer trial. N Engl J Med 336: 980-987, 1997.

2. Glimelius B, Gronberg H, Jarhult J, Wallgren A and CavallinStahl E: A systematic overview of radiation therapy effects in rectal cancer. Acta Oncol 42: 476-492, 2003.

3. Adjuvant radiotherapy for rectal cancer: a systematic overview of 8,507 patients from 22 randomised trials. Lancet 358: 1291-1304, 2001

4. Das P, Skibber JM, Rodriguez-Bigas MA, Feig BW, Chang GJ, Wolff RA, Eng C, Krishnan S, Janjan NA and Crane CH: Predictors of tumor response and downstaging in patients who receive preoperative chemoradiation for rectal cancer. Cancer 109: 1750-1755, 2007.
5. Park HC, Janjan NA, Mendoza TR, Lin EH, Vadhan-Raj S, Hundal M, Zhang Y, Delclos ME, Crane CH, Das P, Wang XS, Cleeland CS and Krishnan S: Temporal patterns of fatigue predict pathologic response in patients treated with preoperative chemoradiation therapy for rectal cancer. Int J Radiat Oncol Biol Phys 75: 775-781, 2009.

6. Kremser C, Trieb T, Rudisch A, Judmaier W and de Vries A: Dynamic $T(1)$ mapping predicts outcome of chemoradiation therapy in primary rectal carcinoma: sequence implementation and data analysis. J Magn Reson Imaging 26: 662-671, 2007.

7. Konski A, Li T, Sigurdson E, Cohen SJ, Small W Jr, Spies S, Yu JQ, Wahl A, Stryker S and Meropol NJ: Use of molecular imaging to predict clinical outcome in patients with rectal cancer after preoperative chemotherapy and radiation. Int $\mathrm{J}$ Radiat Oncol Biol Phys 74: 55-59, 2009.

8. Jiang SM, Wang RB, Yu JM, Zhu KL, Mu DB and Xu ZF: [Correlation of VEGF and KI67 expression with sensitivity to neoadjuvant chemoradiation in rectal adenocarcinoma]. Zhonghua Zhong Liu Za Zhi 30: 602-605, 2008.

9. Kuremsky JG, Tepper JE and McLeod HL: Biomarkers for response to neoadjuvant chemoradiation for rectal cancer. Int $\mathrm{J}$ Radiat Oncol Biol Phys 74: 673-688, 2009.

10. Amundson SA, Do KT, Vinikoor LC, Lee RA, Koch-Paiz CA, Ahn J, Reimers M, Chen Y, Scudiero DA, Weinstein JN, Trent JM, Bittner ML, Meltzer PS and Fornace AJ Jr: Integrating global gene expression and radiation survival parameters across the 60 cell lines of the national cancer institute anticancer drug screen. Cancer Res 68: 415-424, 2008.

11. Correa CR and Cheung VG: Genetic variation in radiationinduced expression phenotypes. Am J Hum Genet 75: 885-890, 2004.

12. Lehnert S: Prediction of tumor response to therapy: molecular markers and the microenvironment. Apoptosis and chips: an overview of the proceedings. Radiat Res 154: 121-124, 2000.

13. Wong YF, Sahota DS, Cheung TH, Lo KW, Yim SF, Chung TK, Chang AM and Smith DI: Gene expression pattern associated with radiotherapy sensitivity in cervical cancer. Cancer J 12: 189-193, 2006

14. Gillham CM, Reynolds J and Hollywood D: Predicting the response of localised oesophageal cancer to neo-adjuvant chemoradiation. World J Surg Oncol 5: 97, 2007.

15. Ghadimi BM, Grade M, Difilippantonio MJ, Varma S, Simon R, Montagna C, Fuzesi L, Langer C, Becker H, Liersch T and Ried T: Effectiveness of gene expression profiling for response prediction of rectal adenocarcinomas to preoperative chemoradiotherapy. J Clin Oncol 23: 1826-1838, 2005.

16. Watanabe T, Komuro Y, Kiyomatsu T, Kanazawa T, Kazama Y, Tanaka J, Tanaka T, Yamamoto Y, Shirane M, Muto T and Nagawa H: Prediction of sensitivity of rectal cancer cells in response to preoperative radiotherapy by DNA microarray analysis of gene expression profiles. Cancer Res 66: 3370-3374, 2006.

17. Dairkee SH, Ji Y, Ben Y, Moore DH, Meng Z and Jeffrey SS: A molecular 'signature' of primary breast cancer cultures; patterns resembling tumor tissue. BMC Genomics 5: 47, 2004.

18. Carmichael J, DeGraff WG, Gazdar AF, Minna JD and Mitchell JB: Evaluation of a tetrazolium-based semiautomated colorimetric assay: assessment of radiosensitivity. Cancer Res 47: 943-946, 1987.

19. de la Monte SM, Lahousse SA, Carter J and Wands JR: ATP luminescence-based motility-invasion assay. Biotechniques 33: 98-100, 2002.

20. International Union Against Cancer. TNM classification of malignant tumors. 6th edition. Wiley-liss, New York, 2002.

21. Janku F, Srovnal J, Korinkova G, Novotny J, Petruzelka L, Power D, Matous B and Hajduch M: Molecular detection of disseminated breast cancer cells in the bone marrow of early breast cancer patients using quantitative RT-PCR for CEA. Neoplasma 55: 317-322, 2008.

22. Chen YF, Wang JY, Wu CH, Chen FM, Cheng TL and Lin SR: Detection of circulating cancer cells with K-ras oncogene using membrane array. Cancer Lett 229: 115-122, 2005.

23. Dennis G Jr, Sherman BT, Hosack DA, Yang J, Gao W, Lane HC and Lempicki RA: David: database for annotation, visualization, and integrated discovery. Genome Biol 4: 3, 2003.

24. Zhong H, Yang X, Kaplan LM, Molony C and Schadt EE: Integrating pathway analysis and genetics of gene expression for genome-wide association studies. Am J Hum Genet 86: 581-591, 2010. 
25. West CM, Davidson SE, Roberts SA and Hunter RD: The independence of intrinsic radiosensitivity as a prognostic factor for patient response to radiotherapy of carcinoma of the cervix. Br J Cancer 76: 1184-1190, 1997.

26. Spitz FR, Giacco GG, Hess K, Larry L, Rich TA, Janjan N, Cleary KR and Skibber JM: p53 immunohistochemical staining predicts residual disease after chemoradiation in patients with high-risk rectal cancer. Clin Cancer Res 3: 1685-1690, 1997.

27. Luna-Perez P, Arriola EL, Cuadra Y, Alvarado I and Quintero A p53 protein overexpression and response to induction chemoradiation therapy in patients with locally advanced rectal adenocarcinoma. Ann Surg Oncol 5: 203-208, 1998.

28. Saw RP, Morgan M, Koorey D, Painter D, Findlay M, Stevens G, Clarke S, Chapuis P and Solomon MJ: p53, deleted in colorectal cancer gene, and thymidylate synthase as predictors of histopathologic response and survival in low, locally advanced rectal cancer treated with preoperative adjuvant therapy. Dis Colon Rectum 46: 192-202, 2003

29. Tannapfel A, Nusslein S, Fietkau R, Katalinic A, Kockerling F and Wittekind C: Apoptosis, proliferation, bax, bcl-2 and p53 status prior to and after preoperative radiochemotherapy for locally advanced rectal cancer. Int J Radiat Oncol Biol Phys 41: 585-591, 1998

30. Kim NK, Park JK, Lee KY, Yang WI, Yun SH, Sung J and Min JS: p53, BCL-2, and KI-67 expression according to tumor response after concurrent chemoradiotherapy for advanced rectal cancer. Ann Surg Oncol 8: 418-424, 2001.

31. Sklar MD: The ras oncogenes increase the intrinsic resistance of NIH 3T3 cells to ionizing radiation. Science 239: 645-647, 1988.

32. Kasid U, Pfeifer A, Weichselbaum RR, Dritschilo A and Mark GE: The raf oncogene is associated with a radiationresistant human laryngeal cancer. Science 237: 1039-1041, 1987.

33. Rodel F, Hoffmann J, Distel L, Herrmann M, Noisternig T, Papadopoulos T, Sauer R and Rodel C: Survivin as a radioresistance factor, and prognostic and therapeutic target for radiotherapy in rectal cancer. Cancer Res 65: 4881-4887, 2005.

34. Ojima E, Inoue Y, Miki C, Mori M and Kusunoki M: Effectiveness of gene expression profiling for response prediction of rectal cancer to preoperative radiotherapy. J Gastroenterol 42: 730-736, 2007

35. Sinclair WK and Morton RA: X-ray sensitivity during the cell generation cycle of cultured chinese hamster cells. Radiat Res 29: 450-474, 1966

36. Sinclair WK: Cyclic x-ray responses in mammalian cells in vitro. Radiat Res 33: 620-643, 1968.

37. Knoops L, Haas R, de Kemp S, Majoor D, Broeks A, Eldering E, de Boer JP, Verheij M, van Ostrom C, de Vries A, van't Veer L and de Jong D: In vivo p53 response and immune reaction underlie highly effective low-dose radiotherapy in follicular lymphoma. Blood 110: 1116-1122, 2007.

38. Gasic GJ: Role of plasma, platelets, and endothelial cells in tumor metastasis. Cancer Metastasis Rev 3: 99-114, 1984.
39. Tohgo A, Tanaka NG and Ogawa H: Platelet-aggregating activities of metastasizing tumor cells. Iv. Effects of cell surface modification on thrombin generation, platelet aggregation and subsequent lung colonization. Invasion Metastasis 6: 58-68, 1986.

40. Rickles FR: Mechanisms of cancer-induced thrombosis in cancer. Pathophysiol Haemost Thromb 35: 103-110, 2006.

41. Ulrich D, Ulrich F, Silny J, Unglaub F and Pallua N: [Chiparraybased identification of gene expression in HUVECS treated with low frequency electric fields]. Handchir Mikrochir Plast Chir 38: 149-155, 2006.

42. Hernandez S, Hernandez L, Bea S, Cazorla M, Fernandez PL, Nadal A, Muntane J, Mallofre C, Montserrat E, Cardesa A and Campo E: Cdc25 cell cycle-activating phosphatases and c-myc expression in human non-Hodgkin's lymphomas. Cancer Res 58: $1762-1767,1998$

43. Wu W, Fan YH, Kemp BL, Walsh G and Mao L: Overexpression of cdc25A and cdc25B is frequent in primary non-small cell lung cancer but is not associated with overexpression of c-myc. Cancer Res 58: 4082-4085, 1998.

44. Nishioka K, Doki Y, Shiozaki H, Yamamoto H, Tamura S, Yasuda T, Fujiwara Y, Yano M, Miyata H, Kishi K, Nakagawa H, Shamma A and Monden M: Clinical significance of CDC25A and $\mathrm{CDC} 25 \mathrm{~B}$ expression in squamous cell carcinomas of the oesophagus. Br J Cancer 85: 412-421, 2001

45. Dixon D, Moyana T and King MJ: Elevated expression of the cdc25A protein phosphatase in colon cancer. Exp Cell Res 240: 236-243, 1998

46. Galaktionov K, Chen X and Beach D: Cdc25 cell-cycle phosphatase as a target of c-myc. Nature 382: 511-517, 1996.

47. Coco Martin JM, Balkenende A, Verschoor T, Lallemand F and Michalides R: Cyclin D1 overexpression enhances radiationinduced apoptosis and radiosensitivity in a breast tumor cell line. Cancer Res 59: 1134-1140, 1999.

48. Miyata H, Doki Y, Shiozaki H, Inoue M, Yano M, Fujiwara Y, Yamamoto H, Nishioka K, Kishi K and Monden M: Cdc25b and $\mathrm{p} 53$ are independently implicated in radiation sensitivity for human esophageal cancers. Clin Cancer Res 6: 4859-4865, 2000.

49. Tannapfel A, Wasner M, Krause K, Geissler F, Katalinic A, Hauss J, Mossner J, Engeland K and Wittekind C: Expression of p73 and its relation to histopathology and prognosis in hepatocellular carcinoma. J Natl Cancer Inst 91: 1154-1158, 1999.

50. Chen X, Arciero CA and Godwin AK: BRCA1-associated complexes: new targets to overcome breast cancer radiation resistance. Expert Rev Anticancer Ther 6: 187-196, 2006.

51. Trojani A, Montillo M, Nichelatti M, Tedeschi A, Colombo C, Veronese S, Mura MA, Ricci F, Scarpati B, Colosimo A, Lodola M and Morra E: ZAP-70, IgVh, and cytogenetics for assessing prognosis in chronic lymphocytic leukemia. Cancer Biomark 6: 1-9, 2010

52. Lane J, Martin TA, Mansel RE and Jiang WG: The expression and prognostic value of the guanine nucleotide exchange factors (GEFs) Trio, Vav1 and TIAM-1 in human breast cancer. Int Semin Surg Oncol 5: 23, 2008. 